\title{
Biodeterioração da madeira no patrimônio histórico - a importância do diagnóstico para o restauro
}

Maria Beatriz Bacellar Monteiro*; Gonzalo Antonio Carballeira Lopez ${ }^{* *}$ Takashi Yojo***

Instituto de Pesquisas Tecnológicas do Estado de São Paulo

Av. Prof. Almeida Prado, 532 - Cidade Universitária

CEP 05508-901 - São Paulo, SP. Telefones: +(11) 3767-4532 / 4389 / 4951

$\underline{\text { www.ipt.br }}$

O Centro de Tecnologia de Recursos Florestais do Instituto de Pesquisas Tecnológicas do Estado de São Paulo - IPT atua no diagnóstico e proposição de soluções técnicas para o controle de insetos e fungos em edificações pertencentes ao patrimônio histórico, incluindo a avaliação do comprometimento de estruturas de madeira.

Este resumo toma como exemplo um dos trabalhos realizados pelo IPT no madeiramento estrutural de ginásio poliesportivo situado dentro do complexo do Estádio Municipal "Paulo Machado de Carvalho", no Pacaembu, São Paulo (Figura 1) e pretende comentar a importância do correto diagnóstico dos problemas de biodeterioração na orientação dos trabalhos de restauro.

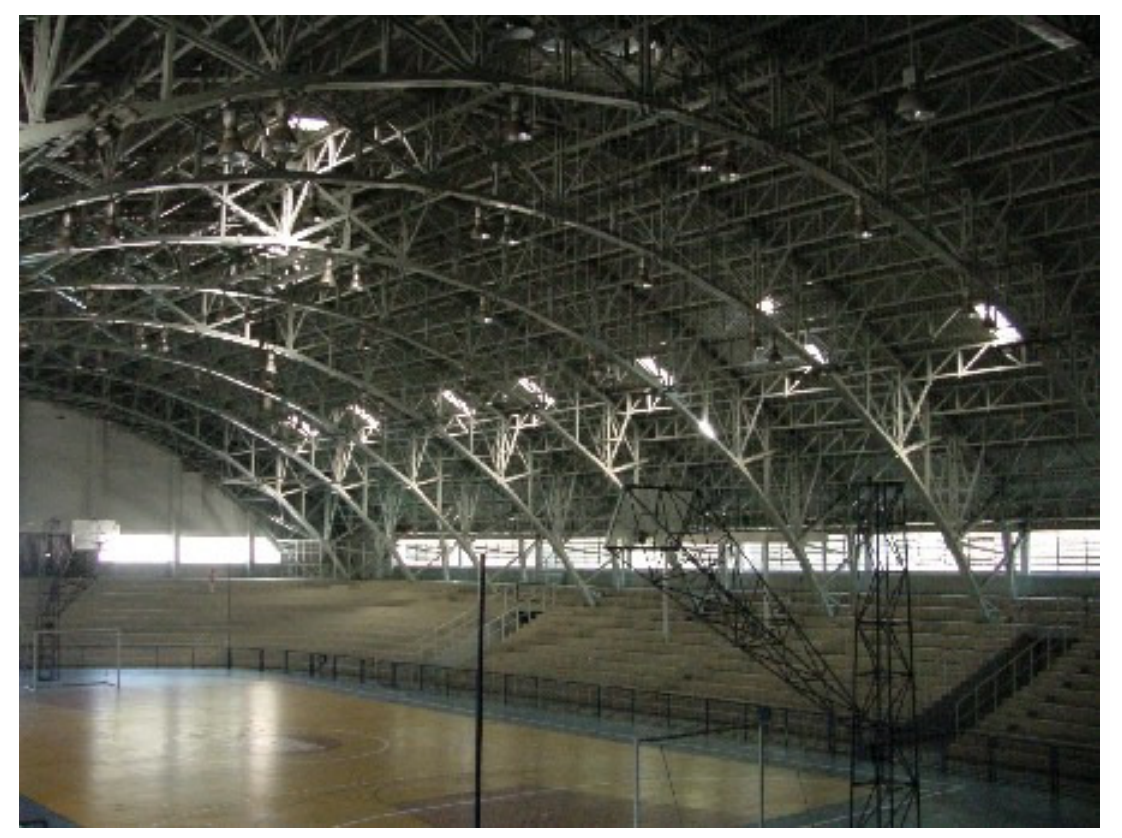

FIGURA 1 - Vista interna do Ginásio Municipal do Pacaembu.

O trabalho iniciou-se a partir da constatação da ocorrência de cupins em alguns dos apoios dos doze arcos de madeira componentes da estrutura de cobertura. 


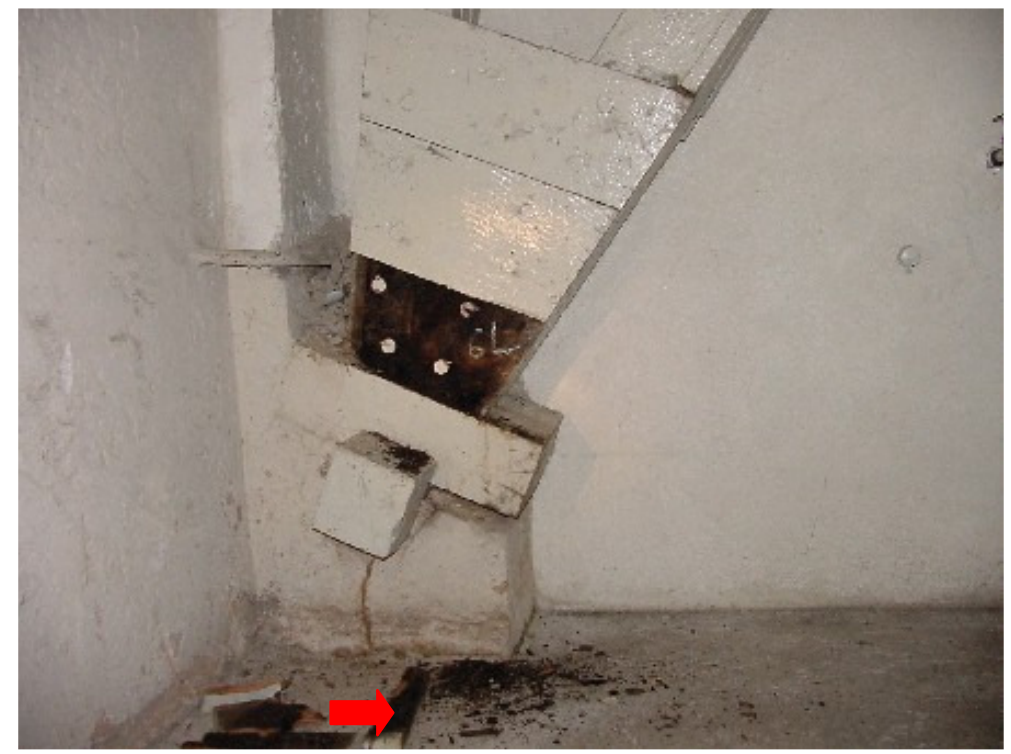

FIGURA 2 - Túnel de cupim junto a apoio de arco.

Para o mapeamento da biodeterioração, as peças de madeira de todos os arcos foram inspecionadas quanto à sanidade biológica, com a exposição de alguns dos apoios que se encontravam escondidos por chapas metálicas ou paredes.

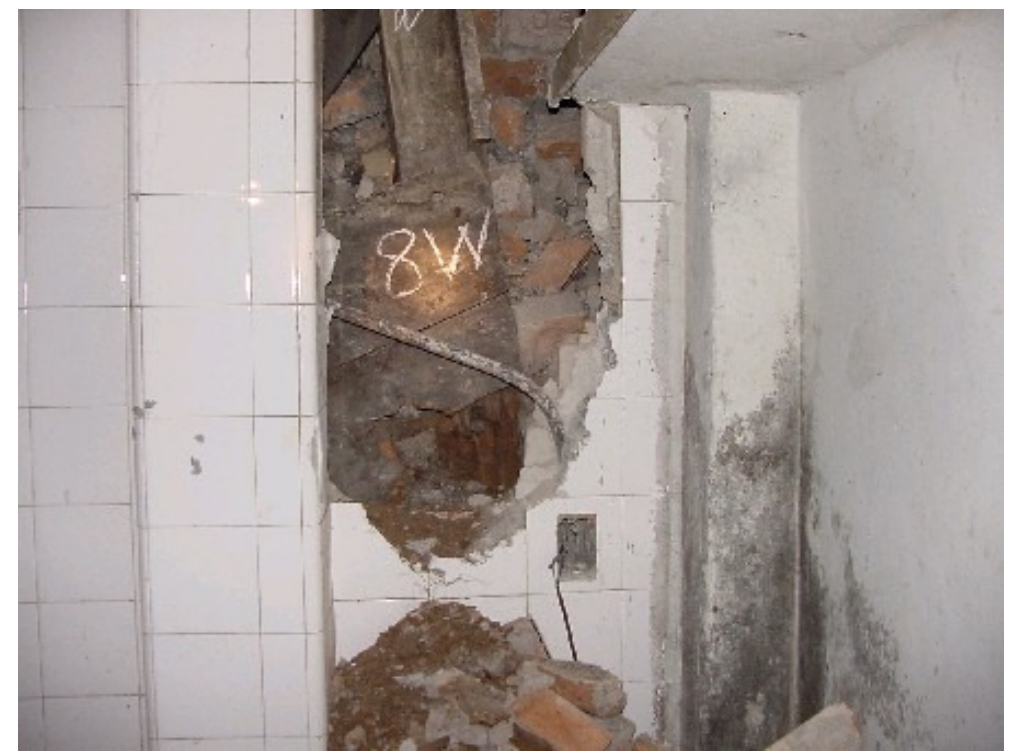

FIGURA 3 - Apoio de arco embutido em parede.

Concomitantemente, foi realizado o levantamento das características geométricas da estrutura como um todo e a identificação botânica das peças de madeira utilizadas na composição dos arcos.

Como resultado do levantamento constatou-se que os arcos, confeccionados com a madeira de peroba-rosa (Aspidosperma cf. polyneuron, família Apocynaceae), apresentavam, em sua região de apoio, um estado que variava de sadio até 
completamente destruído pelo ataque de fungos apodrecedores e/ou cupinssubterrâneos.

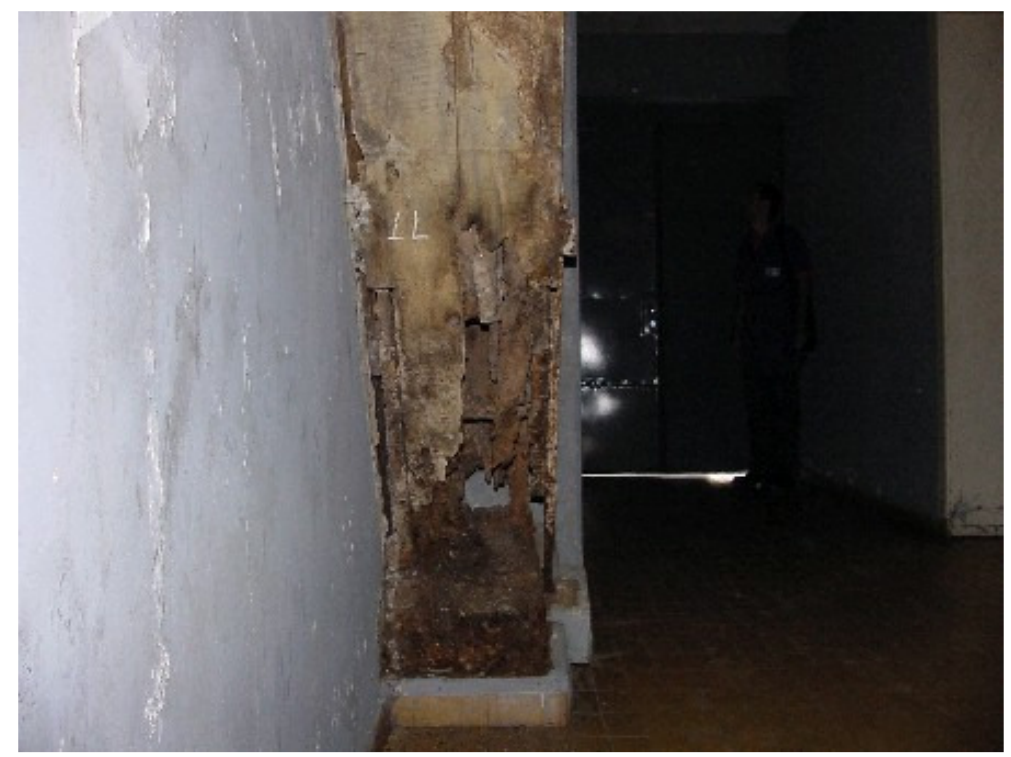

FIGURA 4 - Apoio de arco intensamente deteriorado.

O mapeamento detalhado da biodeterioração dos apoios está representado na Figura 5 que indica o tipo de organismo encontrado e a intensidade de ataque observada.

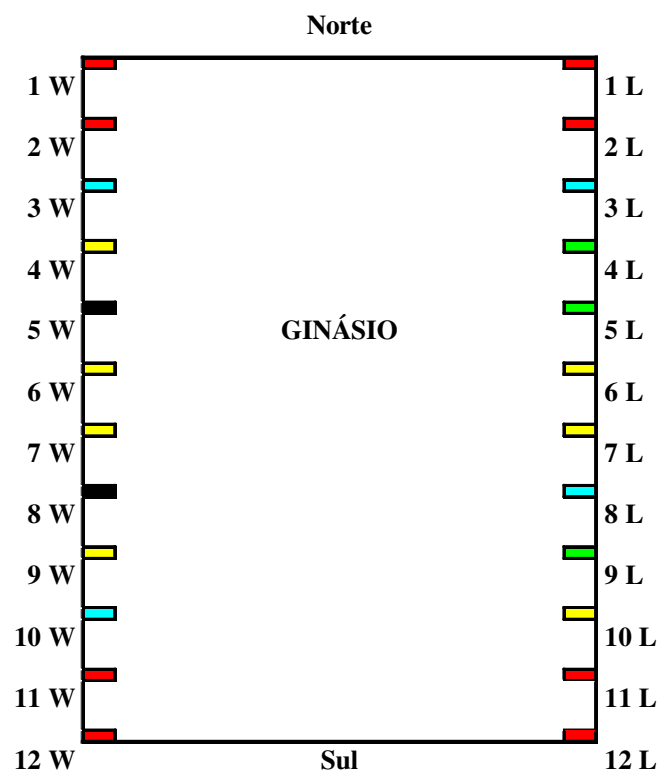

apoio totalmente destruído (fungos e cupins)

ataque intenso de fungos e/ou cupins

desgaste superficial de cupins

apoio embutido em parede - totalmente destruído

FIGURA 5 - Desenho esquemático do ginásio, indicando o tipo de organismos e a intensidade de ataque na região de apoio dos arcos. 
A análise estrutural considerou as características do projeto original e o estado atual em que a estrutura foi encontrada, concluindo que, já no projeto original, a estrutura apresentava algumas deficiências nas ligações entre travamentos e arcos, que comprometiam a estabilidade da estrutura. Se considerada a situação atual, na qual a rigidez e resistência mecânica nos elementos estruturais dos arcos variam devido aos diferentes graus de deterioração das peças, observam-se sobrecargas maiores na estrutura como um todo e uma distribuição de esforços diferente da prevista no projeto original, indicando que as condições mínimas de segurança exigidas por norma não são atendidas.

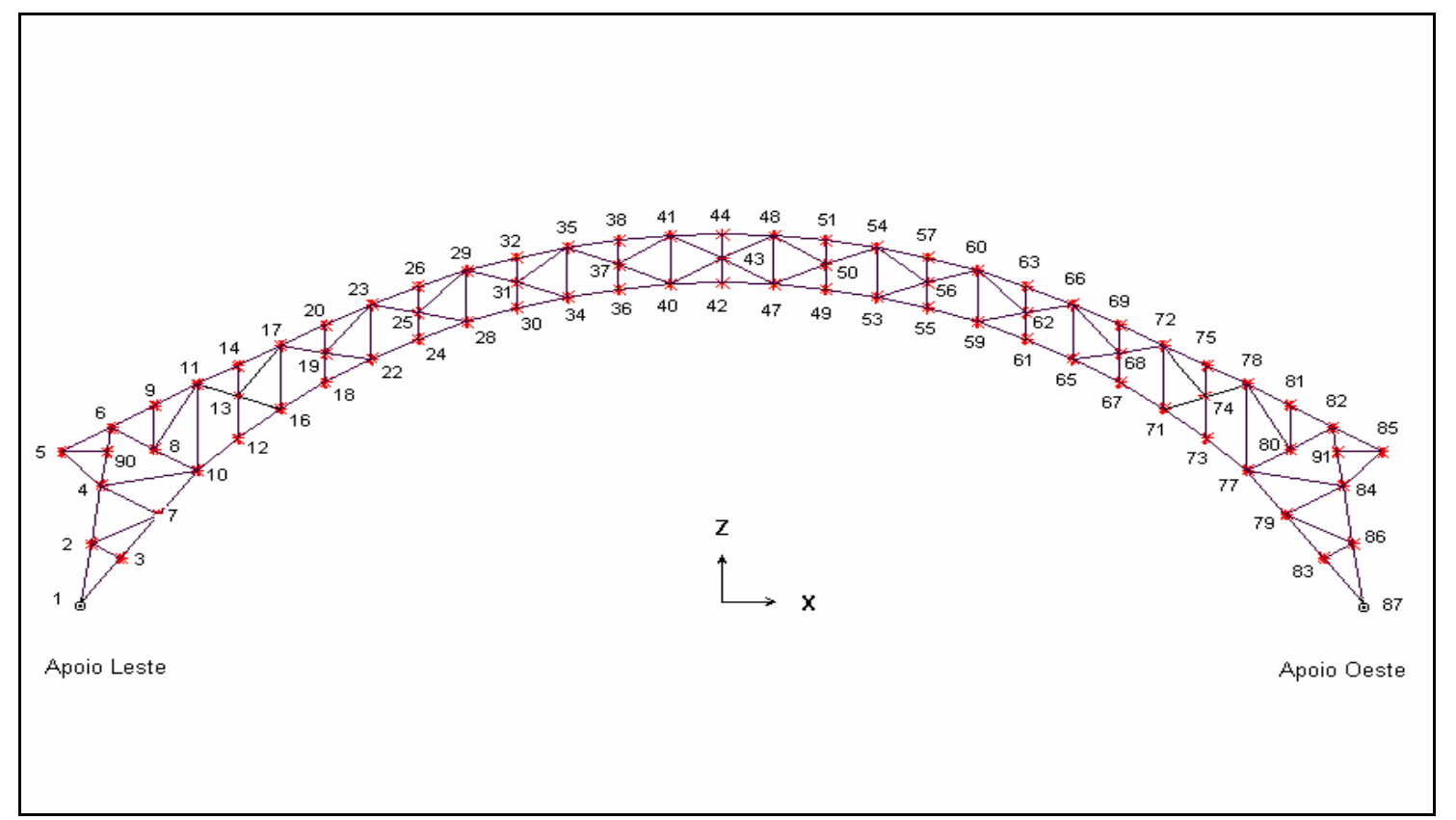

FIGURA 6 - Esquema dos arcos utilizado para as análises estruturais.

Concluindo, a avaliação detalhada da sanidade biológica das peças de madeira e o levantamento concomitante das características geométricas atuais das estruturas, realizado por equipe multidisciplinar, permitem o diagnóstico correto dos problemas no madeiramento da edificação, devendo sempre anteceder o início dos trabalhos de restauro. Além disso, servem como base para a realização de análises estruturais que permitirão dizer se a estrutura atende ou não aos requisitos de segurança exigidos. A partir da integração dos resultados obtidos é possível selecionar as medidas preventivas e corretivas mais adequadas para a conservação do patrimônio, planejando as intervenções em conjunto com outras estratégias para o restauro. 


\section{Créditos}

* Bióloga. Mestre em Ciência e Tecnologia de Madeiras. Laboratório de Preservação de Madeiras e Biodeterioração de Materiais - Centro de Tecnologia de Recursos Florestais - Instituto de Pesquisas Tecnológicas.

e-mail: $\underline{\text { mbbmonte@ipt.br }}$

** Biólogo. Laboratório de Preservação de Madeiras e Biodeterioração de Materiais - Centro de Tecnologia de Recursos Florestais - Instituto de Pesquisas Tecnológicas.

e-mail: gonzalo@ipt.br

*** Engenheiro Civil. Doutor em Engenharia de Estruturas. Laboratório de Madeira e Produtos Derivados - Centro de Tecnologia de Recursos Florestais - Instituto de Pesquisas Tecnológicas. e-mail: yojos@ipt.br 